\title{
Correction: Atomic force microscopy reveals new biophysical markers for monitoring subcellular changes in oxidative injury: Neuroprotective effects of quercetin at the nanoscale
}

Maja Jazvinšćak Jembrek, Josipa Vlainić, Vida Čadež, Suzana Šegota

Fig 2 is incorrect. Please see the correct Fig 2 here.

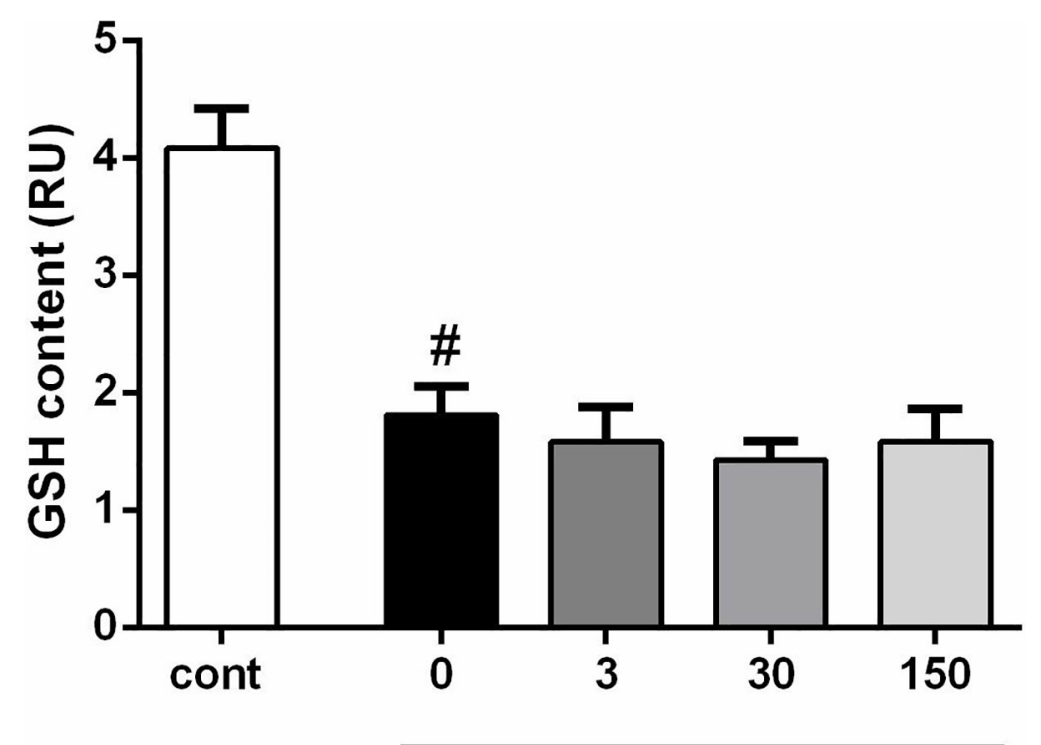

$1.5 \mathrm{mM} \mathrm{H}_{2} \mathrm{O}_{2}+$ querc. $(\mu \mathrm{M})$

Citation: Jazvinšćak Jembrek M, Vlainić J, Čadež V Šegota S (2019) Correction: Atomic force microscopy reveals new biophysical markers for monitoring subcellular changes in oxidative injury: Neuroprotective effects of quercetin at the nanoscale. PLoS ONE 14(2): e0212150. https://doi. org/10.1371/journal.pone.0212150

Published: February 6, 2019

Copyright: @ 2019 Jazvinšćak Jembrek et al. This is an open access article distributed under the terms of the Creative Commons Attribution License, which permits unrestricted use, distribution, and reproduction in any medium, provided the original author and source are credited. 